\title{
Divergent signaling pathways cooperatively regulate TGF $\beta$ induction of cysteine-rich protein 2 in vascular smooth muscle cells
}

\author{
Meng-Ling Wu ${ }^{1,2}$, Chung-Huang Chen 1,3, Yung-Tsang Lin ${ }^{1}$, Yuan-Jyun Jheng ${ }^{1}$, Yen-Chun Ho ${ }^{1,4}$, Liang-Tung Yang ${ }^{1}$,
} Linyi Chen ${ }^{2}$, Matthew D Layne ${ }^{5}$ and Shaw-Fang Yet ${ }^{1,6,7^{*}}$

\begin{abstract}
Background: Vascular smooth muscle cells (VSMCs) of the arterial wall play a critical role in the development of occlusive vascular diseases. Cysteine-rich protein 2 (CRP2) is a VSMC-expressed LIM-only protein, which functionally limits VSMC migration and protects against pathological vascular remodeling. The multifunctional cytokine TGF $\beta$ has been implicated to play a role in the pathogenesis of atherosclerosis through numerous downstream signaling pathways. We showed previously that TGF $\beta$ upregulates CRP2 expression; however, the detailed signaling mechanisms remain unclear.

Results: TGF $\beta$ treatment of VSMCS activated both Smad2/3 and ATF2 phosphorylation. Individually knocking down Smad2/3 or ATF2 pathways with siRNA impaired the TGF $\beta$ induction of CRP2, indicating that both contribute to CRP2 expression. Inhibiting TRRI kinase activity by SB431542 or TRRI knockdown abolished Smad2/3 phosphorylation but did not alter ATF2 phosphorylation, indicating while Smad2/3 phosphorylation was TßRI-dependent ATF2 phosphorylation was independent of TRRI. Inhibiting Src kinase activity by SU6656 suppressed TGF $\beta$-induced RhoA and ATF2 activation but not Smad2 phosphorylation. Blocking ROCK activity, the major downstream target of RhoA, abolished ATF2 phosphorylation and CRP2 induction but not Smad2 phosphorylation. Furthermore, JNK inhibition with SP600125 reduced TGFß-induced ATF2 (but not Smad2) phosphorylation and CRP2 protein expression while ROCK inhibition blocked JNK activation. These results indicate that downstream of T $\beta R I I$, Src family kinase-RhoA-ROCK-JNK signaling pathway mediates TRRI-independent ATF2 activation. Promoter analysis revealed that the TGF $\beta$ induction of CRP2 was mediated through the CRE and SBE promoter elements that were located in close proximity.
\end{abstract}

Conclusions: Our results demonstrate that two signaling pathways downstream of TGF $\beta$ converge on the CRE and SBE sites of the Csrp2 promoter to cooperatively control CRP2 induction in VSMCs, which represents a previously unrecognized mechanism of VSMC gene induction by TGF $\beta$.

Keywords: Cysteine-rich protein 2, Vascular smooth muscle cells, TGF $\beta$, ATF2, Smad2/3

\section{Background}

Vascular smooth muscle cells (VSMCs) in the tunica media of the arteries play important roles in regulating blood pressure and vascular tone. In normal vessels, these VSMCs exhibit a quiescent and differentiated phenotype and express proteins involved in the contractile functions such as

\footnotetext{
* Correspondence: syet@nhri.org.tw

${ }^{1}$ Institute of Cellular and System Medicine, National Health Research Institutes, Zhunan, Taiwan

${ }^{6}$ Metabolomic Research Center, China Medical University Hospital, Taichung, Taiwan

Full list of author information is available at the end of the article
}

smooth muscle (SM) myosin heavy chain and SM $\alpha$-actin. However, in contrast to striated muscle cells, adult VSMCs retain significant plasticity, known as phenotypic modulation. In response to arterial injury, VSMCs de-differentiate, downregulate SM marker genes, and change to a proliferative and migratory phenotype, leading to lesion formation and occlusive vascular disease [1]. Thus, preventing this dedifferentiation might be a potential therapeutic strategy for treating vascular disease.

Cysteine-rich protein (CRP) 2, a LIM-only CRP family member [2], is highly expressed in VSMCs [3,4].

\section{Biomed Central}

(c) 2014 Wu et al.; licensee BioMed Central Ltd. This is an Open Access article distributed under the terms of the Creative Commons Attribution License (http://creativecommons.org/licenses/by/2.0), which permits unrestricted use, distribution, and reproduction in any medium, provided the original work is properly credited. The Creative Commons Public Domain Dedication waiver (http://creativecommons.org/publicdomain/zero/1.0/) applies to the data made available in this article, unless otherwise stated. 
Importantly, balloon or wire artery injury reduces CRP2 expression [3,4], suggesting a critical role for CRP2 in the response to vascular injury. By gene deletion experiments, we demonstrated that a lack of CRP2 enhanced VSMC migration into the intima and increased neointima formation following arterial injury [4]. Our recent study determined that CRP2 sequesters the scaffold protein p130Cas at focal adhesions, controls lamellipodia formation and reduces cell motility. These CRP2-p130Cas complexes function to blunt VSMC migration [5]. Therefore, maintaining or upregulating CRP2 expression during vascular injury might serve as a protective mechanism against intimal thickening.

The multifunctional cytokine TGF $\beta$ contributes to the pathogenesis of atherosclerosis and restenosis $[1,6]$. During progressive intimal thickening following balloon angioplasty, neointimal SMCs produce TGF $\beta$ and it acts as a growth regulatory factor [6]. The importance of this autocrine TGF $\beta$ pathway in vascular disease was established through studies selectively inhibiting TGF $\beta$ mRNA in a rat vascular injury model in vivo, which resulted in blunted neointimal formation [7]. Some of the effects of TGF $\beta$ in VSMCs are controversial. For example, serum concentrations of active TGF $\beta$ are significantly reduced in patients with advanced atherosclerosis, suggesting TGF $\beta$ is a key inhibitor of atherosclerosis [8]. TGF $\beta$ stimulates SMC differentiation marker gene expression $[1,9,10]$ and inhibition of TGF $\beta$ signaling using neutralizing anti-TGF $\beta$ antibodies accelerates the development of atherosclerotic lesions in apoE-deficient mice [11]. Further supporting a protective role of TGF $\beta$ against vascular lesion formation, targeted disruption of TGF $\beta$-Smad3 signaling enhances neointimal hyperplasia after arterial injury [12].

We identified in a previous study that TGF $\beta$ induces CRP2 expression in VSMCs and TGF $\beta$ treatment reduces wild type but not Csrp2 (mouse CRP2 gene symbol)-deficient VSMC migration, demonstrating the functional importance of CRP2 induction by TGF $\beta$ in regulating VSMC migration [13]. TGF $\beta$ upregulates CRP2 expression via a CRE promoter element and transcription factor ATF2 [13]; however, the detailed signaling mechanisms underlying TGF $\beta$ induction of CRP2 remain unclear. The goal of the present study was to delineate the signaling pathways by which TGF $\beta$ upregulates CRP2 expression, which might provide an opportunity for developing targeted strategies to reduce intimal thickening.

\section{Results}

TGF $\beta$ induces CRP2 expression through Smad2/3 and ATF2

To investigate the signaling pathways that mediate CRP2 induction by TGF $\beta$, we first examined type I TGF $\beta$ receptor (T $\beta$ RI) downstream signaling. We pretreated VSMCs with vehicle or T $\beta R I$ kinase inhibitor SB431542 for $30 \mathrm{~min}$, followed by stimulation with or without
TGF $\beta$ for $24 \mathrm{~h}$ and then examined CRP2 expression levels. SB431542 significantly reduced TGF $\beta$-induced CRP2 expression (Figure 1A), indicating T $\beta R I$ kinase activity is required for TGF $\beta$ induction of CRP2. It is well established that Smad2/3 transmits TGF $\beta$ signaling [14], thus we examined Smad2/3 activation. Indeed, TGF $\beta$ increased phosphorylation levels of Smad2 and Smad3 in VSMCs (Figure 1B). In addition, as previously reported [13], TGF $\beta$ also increased ATF2 phosphorylation (Figure 1B). Interestingly, SB431542 blocked TGF $\beta$ induced activation of Smad2 and Smad3 but did not block ATF2 phosphorylation (Figure 1B). PI3K has also been implicated in TGF $\beta$ signaling [15], thus we determined whether PI3K pathways participate in this regulation by treating cells with PI3K inhibitors. Wortmannin or LY294002 did not affect ATF2 or Smad2/3 phosphorylation (Figure 1B). These results suggest that in VSMCs, T $\beta R I$ mediates TGF $\beta$ activation of $\operatorname{Smad} 2 / 3$ whereas neither T $\beta R I$ kinase activity nor PI3K signaling is involved in TGF $\beta$ dependent stimulation of ATF2. To define the role of Smad2/3 and ATF2 in CRP2 upregulation, we used siRNA to suppress their expression. In comparison with control siRNA, knockdown of Smad2/3 or ATF2 abrogated TGF $\beta$ induced CRP2 expression (Figure 1C-D), supporting the concept that both Smad2/3 and ATF2 contribute to CRP2 induction.

\section{ATF2 activation by TGF $\beta$ is independent of TAK1 and TRAF6}

It has been shown in epithelial cells and fibroblasts that independent of T $\beta R I$ kinase activity, TGF $\beta$ activates TAK1 signaling through interaction of T $\beta$ RI with TRAF6, whereas Smad2 activation is not dependent on TRAF6 $[16,17]$. Thus, we examined whether TGF $\beta$ activates ATF2 through TAK1 and TRAF6 in VSMCs. We transfected VSMCs with siRNA to TAK1 or TRAF6, or control siRNA and then stimulated cells with or without TGF $\beta$ for $10 \mathrm{~min}$. Western blot analysis showed that knocking down TAK1 did not alter ATF2 activation although it partially reduced Smad2 phosphorylation (Figure 2A), indicating TAK1 was not involved in TGF $\beta$-induced ATF2 phosphorylation in VSMCs. TRAF6 knockdown did not affect TGF $\beta$-induced ATF2 or Smad2 phosphorylation (Figure 2B). Moreover, knocking down TRAF6 did not abrogate TGF $\beta$ induction of CRP2 protein expression after $24 \mathrm{~h}$ (Figure $2 \mathrm{C}$ ).

\section{T $\beta R$ I kinase-independent ATF2 activation by TGF $\beta$}

Upon ligand binding, TRRII recruits TRRI into an active heterotetrameric signaling complex and transphosphorylates T $\beta R I$ to activate its kinase function [18]. T $\beta R I$ can then phosphorylate Smad2/3 for TGF $\beta$ signaling. Interestingly, we found that inhibiting T $\beta R I$ kinase activity blocked TGF $\beta$-induced Smad2/3 but not ATF2 activation (Figure 1B). This ATF2 phosphorylation is not mediated through TRAF6 either (Figure 2). To confirm further that 


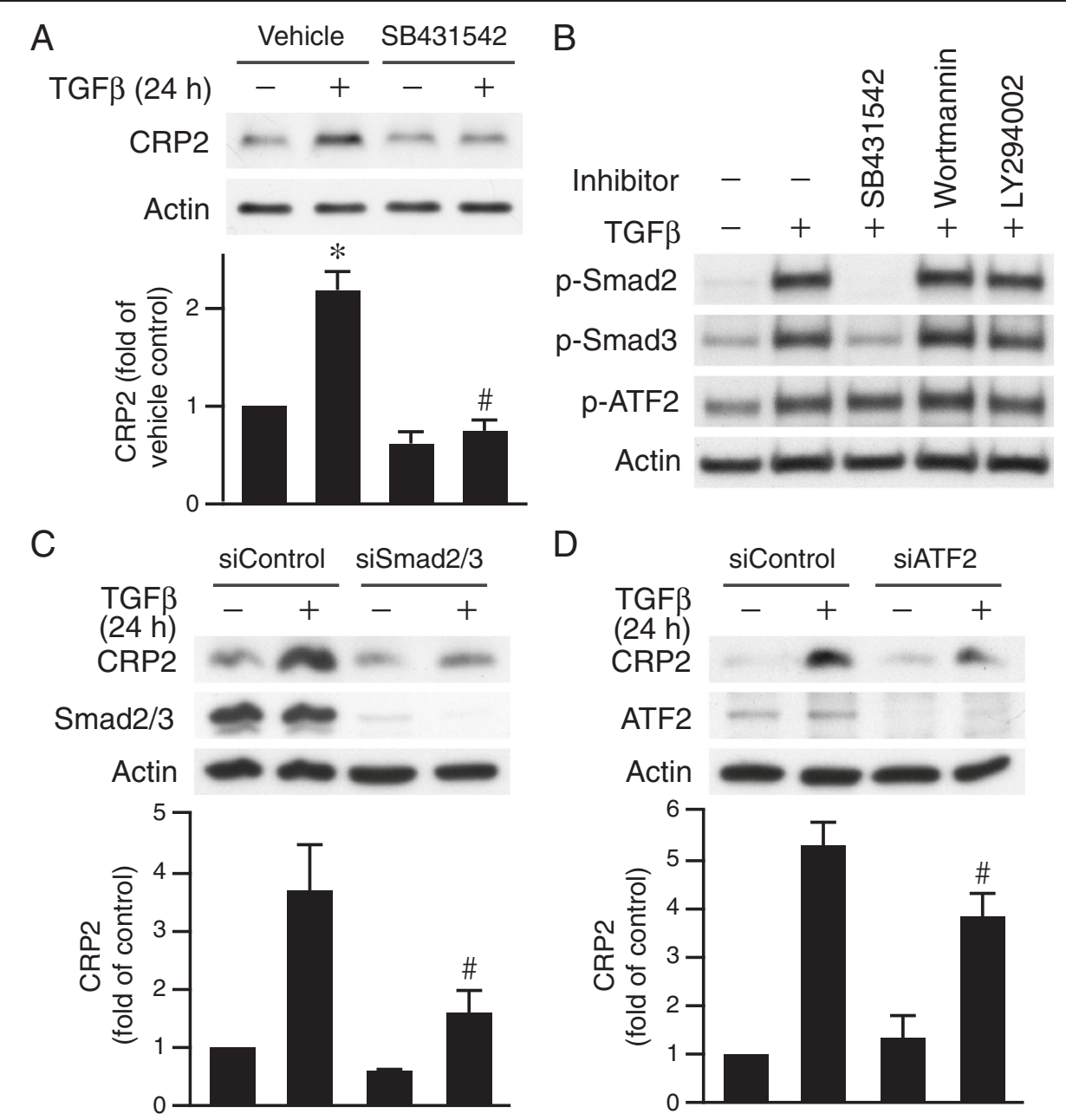

Figure 1 TGF $\beta$ induces CRP2 expression through Smad2/3 and ATF2. (A) TRRI kinase activity contributes to CRP2 induction. VSMCS were

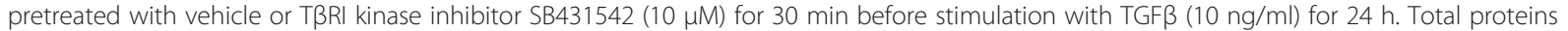
were then harvested for Western blot analysis to detect CRP2 expression. SB431542 significantly decreased TGF $\beta$-induced CRP2 expression. Values are mean \pm S.E. of at least three experiments. ${ }^{*} P<0.05$ vs. control $(-$ TGF $\beta) ;{ }^{*} P<0.05$ vs. TGF $\beta$-stimulated vehicle group. (B) TRRI kinase activity is required for activation of Smad2/3 but not ATF2. VSMCs were pretreated with vehicle, SB431542, PI3K inhibitor Wortmannin (1 $\mu$ M), or LY294002 $(10 \mu \mathrm{M})$ for $30 \mathrm{~min}$ prior to stimulation with or without TGF $\beta$ for $15 \mathrm{~min}$. Activation of Smad2/3 and ATF2 was then determined with Western blot analysis. (C-D) VSMCs were transfected with $20 \mathrm{nM}$ control siRNA, Smad2/3 siRNA (C) or ATF2 siRNA (D) using Lipofectamine RNAiMAX transfection reagent and then stimulated with or without TGF $\beta$ for $24 \mathrm{~h}$. Western blot analysis was performed to detect CRP2, Smad2/3, or ATF2 levels. The membranes were subsequently probed with actin for loading control. Values are mean \pm S.E. of at least three experiments. ${ }^{\#} P<0.05$ vs. TGF $\beta$-stimulated siControl group.

ATF2 phosphorylation is independent of T $\beta R I$, we knocked down TRRI expression using siRNA. Silencing of T $\beta R I$ abrogated TGF $\beta$-induced Smad2 phosphorylation but not ATF2 phosphorylation (Figure 3A), suggesting indeed T $\beta R I$ is not required for TGF $\beta$-induced ATF2 activation.

Type III TGF $\beta$ receptor (T $\beta R I I I)$ has been demonstrated to bind and present TGF $\beta$ to type II TGF $\beta$ receptor (TRRII), thereby increases type II receptor binding affinity and cell responsiveness to TGF $\beta$ [19]. To determine whether TRRIII participates in the ATF2 activation, we knocked down T $\beta$ RIII levels in VSMCs by T $\beta$ RIII siRNA, cells were then stimulated with or without TGF $\beta$. Compared with control siRNA, knocking down
TRRIII levels did not affect the activation of ATF2 or Smad2 at the 10 min early time point (Figure 3B) or affecting CRP2 protein expression $24 \mathrm{~h}$ later (data not shown). These results suggest that T $\beta R I I I$ did not affect TGF $\beta$ signaling in the CRP2 induction. We then knocked down TRRII expression by siRNA and examined phosphorylation of these signaling molecules. Silencing TBRII not only reduced ATF2 activation but also that of Smad2 (Figure 3C), indicating the critical importance of TRRII in mediating TGF $\beta$ signaling. To further assess the role of T $\beta R I I$, we transfected VSMCs with a dominant-negative type II receptor $\operatorname{HA}-\mathrm{T} \beta \mathrm{RII}(\Delta \mathrm{Cyt})$ [20], which has an HA tag at the N-terminus but lacks 


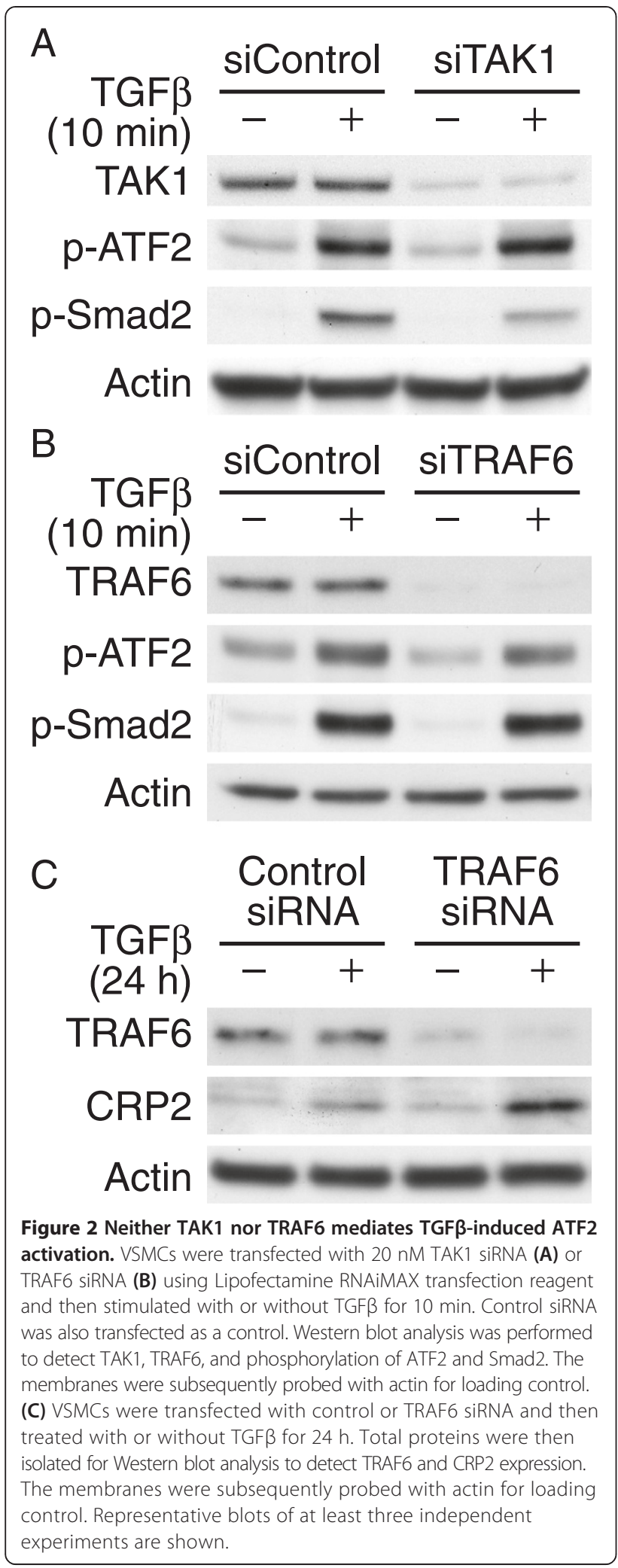

C-terminal kinase domain and is thus incapable of phosphorylating and activating the type I receptor. Interestingly, T $\beta \operatorname{RII}(\Delta \mathrm{Cyt})$ attenuated Smad2 phosphorylation as expected but not the activation of ATF2 (Figure 3D). In addition, T $\beta R I I(\Delta C y t)$ attenuated TGF $\beta$-induced CRP2 expression $24 \mathrm{~h}$ later (Figure 3E).

\section{Src family kinase mediates T $\beta$ RII-dependent TGF $\beta$ activation of RhoA-ROCK and ATF2 in VSMCs}

We next investigated how T $\beta$ RII mediates ATF2 activation independent of T $\beta R I$ in VSMCs. In JEG3 choriocarcinoma cells, Src kinase is involved in TGF $\beta$-induced early signaling [21]. In addition, c-Src has been reported to mediate TGF $\beta$ induced SMC gene expression [22]. We therefore examined whether in VSMCs Src activation was required to transmit TGF $\beta$ signaling for ATF2 activation. The selective Src family kinase inhibitor SU6656 dose dependently abrogated TGFß-induced ATF2 activation (Figure 4A). In contrast, SU6656 did not alter Smad2 phosphorylation by TGF $\beta$ even at high doses (Figure 4A). These data indicate that $\mathrm{Src}$ family kinase functions downstream of T $\beta R I I$ in transducing Smad-independent TGF $\beta$ signaling to activate ATF2. Since rapid Src activation by TGF $\beta$ has been found to effectively activate Small GTPase RhoA in other cell systems [21], we then examined whether in VSMCs RhoA was activated downstream of Src family kinase. Indeed, TGF $\beta$ enhanced RhoA activation and SU6656 inhibited TGF $\beta$ induced RhoA activation (Figure 4B). Furthermore, transfection of VSMCs with control or RhoA siRNA revealed that RhoA knockdown attenuated TGF $\beta$-induced ATF2 activation but not that of Smad2 (Figure 4C). In addition, siRNA-mediated silencing of RhoA not only decreased activation of the signaling molecules at the early time point (Figure 4C) but also reduced TGF $\beta$-induced CRP2 protein expression after 24 h (Figure 4D). These results suggest that Src family kinase-RhoA signaling mediates T $\beta R I I-$ dependent ATF2 activation and CRP2 expression by TGF $\beta$.

Since RhoA kinase (ROCK) is a major target of RhoA and that ROCK has been implicated in SMC differentiation by modulating TGF $\beta$-Smad signaling [23], we examined whether ROCK functioned downstream of RhoA to regulate ATF2 activation. Interestingly, treatment of VSMCs with ROCK inhibitor Y-27632 abolished ATF2 phosphorylation but not that of Smad2 (Figure 5A). Supporting this notion, Y-27632 abrogated TGF $\beta$-induced CRP2 protein expression after $24 \mathrm{~h}$ (Figure $5 \mathrm{~B}$ ).

\section{JNK activation is required for TGF $\beta$-induced phosphorylation} of ATF2

Because MAP kinase pathways have been shown to contribute to TGF $\beta$ signaling $[24,25]$, we evaluated activation of MAP kinase pathway in ATF2 phosphorylation. TGF $\beta$ increased phosphorylation of JNK, p38, and ERK1/2 (Figure 6A). However, kinase inhibitor studies revealed that JNK inhibitor SP600125 but not p38 MAP kinase inhibitor SB203580 or ERK inhibitor U0126 abolished ATF2 phosphorylation (Figure 6A). 


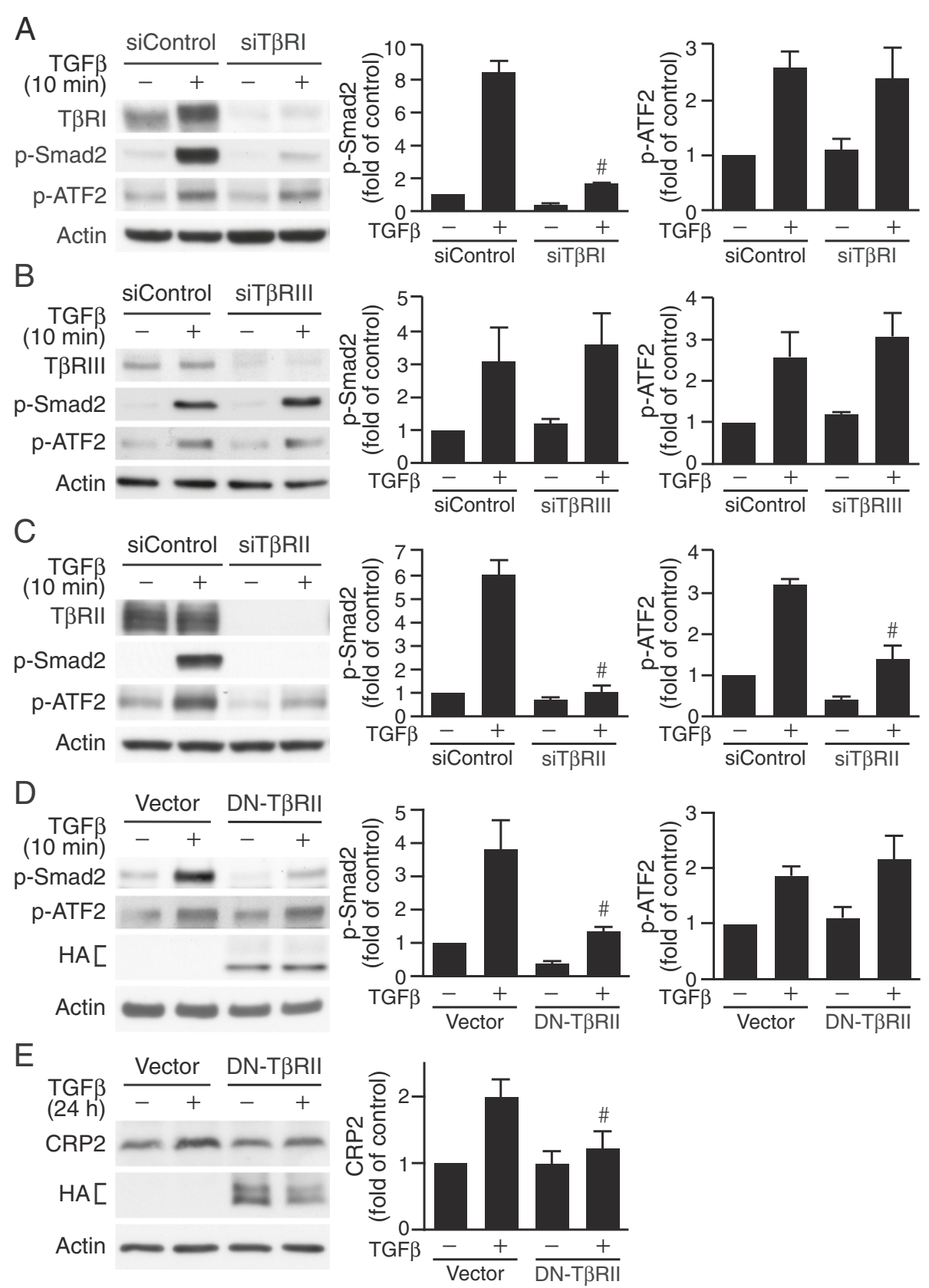

Figure 3 Type II TGF $\beta$ receptor is crucial in mediating TGF $\beta$-induced ATF2 signaling. (A-C) VSMCs were transfected with $20 \mathrm{nM}$ control siRNA or siRNA to different types of TGF $\beta$ receptors. Following $24 \mathrm{~h}$ recovery in growth media and $24 \mathrm{~h}$ serum-starvation, cells were stimulated with or without TGF $\beta$ for 10 min. Western blot analysis was performed to detect different TGF $\beta$ receptor expression levels and phosphorylation of Smad2 and ATF2. (A) TRRI knockdown inhibits Smad2 phosphorylation but not that of ATF2. ${ }^{\#} P<0.05$ vs. TGF $\beta$-stimulated siControl group. (B) TRRIII knockdown does not affect TGF $\beta$ activation of ATF2 or Smad2. (C) TBRII knockdown attenuates TGF $\beta$ activation of ATF2 and Smad2. $\# P<0.05$ vs. TGF $\beta$-stimulated siControl group. (D) Dominant-negative T $\beta R I I$ (DN-T $\beta R I I)$ impairs Smad2 but not ATF2 activation. VSMCs

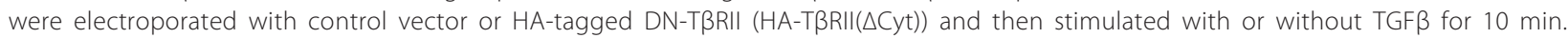
Western blot analysis was performed to assess phosphorylation of Smad2 and ATF2. Overexpression of DN-T $\beta R I I$ was evaluated by probing Western blots with HA antibody. ${ }^{\#} P<0.05$ vs. TGF $\beta$-stimulated vector control group. (E) DN-T $\beta R I l$ impairs TGF $\beta$-induced CRP2 induction. VSMCs were electroporated with control vector or HA-TBRII( $\triangle C y \mathrm{t})$ and stimulated with TGF $\beta$ for $24 \mathrm{~h}$. Total proteins were then isolated for Western blot analysis to detect CRP2 protein levels. The blots were then probed with HA antibody to detect HA-TBRII( $\triangle C$ Cyt) expression. ${ }^{\#} P<0.05$ vs. TGF $\beta$-stimulated vector control group. The membranes were subsequently probed with actin for loading control. Representative blots of at least three independent experiments are shown. 
A
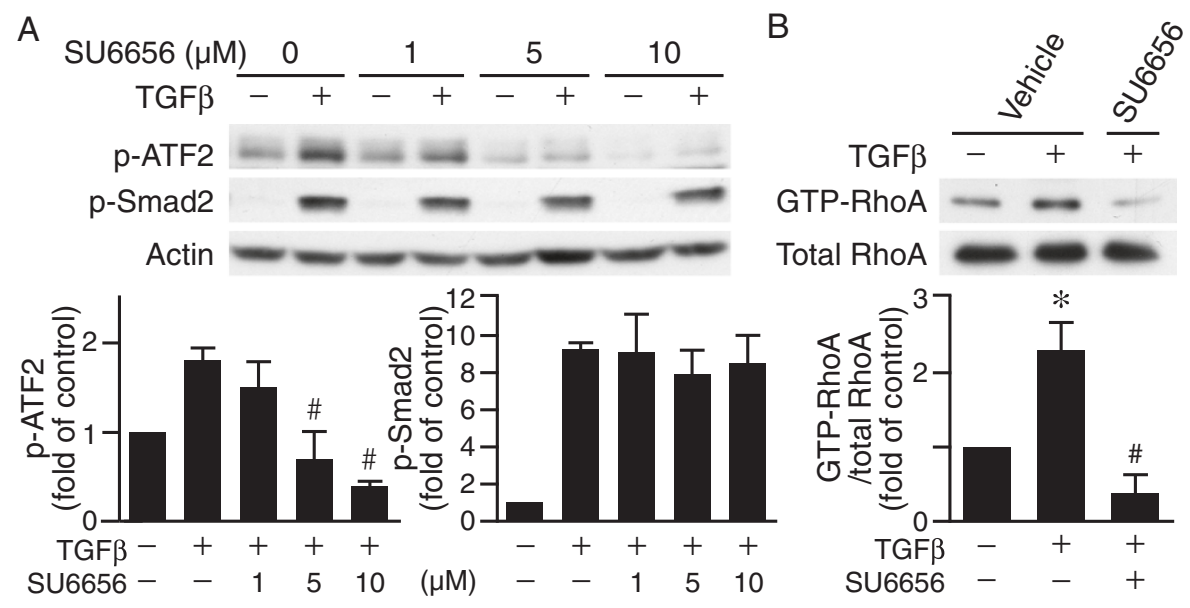

Total RhoA

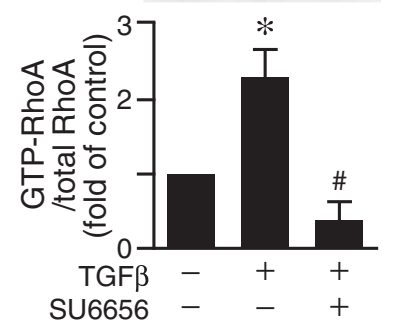

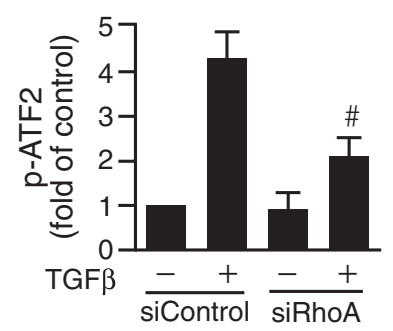
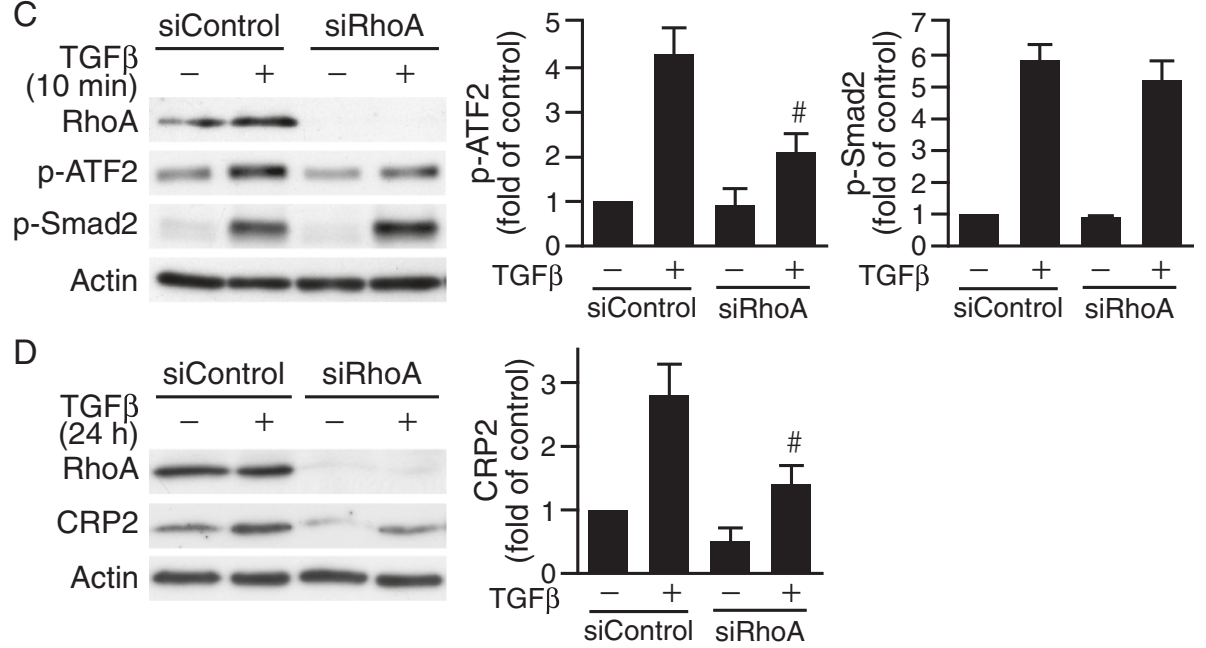

Figure 4 Src family kinase mediates T $\beta$ RII-dependent TGF $\beta$ activation of RhoA and ATF2 in VSMCs. (A) Src family kinase inhibitor SU6656 dose-dependently reduces TGF $\beta$ activation of ATF2 but not that of Smad2. VSMCs were pretreated with increasing concentrations of SU6656 for 30 min and then stimulated with TGF $\beta$ for 10 min. Phosphorylation of ATF2 and Smad 2 was determined by Western blot analysis. The membranes were subsequently probed with actin for loading control. ${ }^{~} P<0.05$ vs. TGF $\beta$-stimulated but without SU6656 treatment group. (B) SU6656 abolishes TGF $\beta$-induced RhoA activation. VSMCs were pretreated with $5 \mu \mathrm{M}$ SU6656 for 30 min prior to stimulation with TGF $\beta$ for 10 min. RhoA activation was then determined by GST-Rhotekin-RBD assays. GTP-RhoA was subsequently eluted and subjected to Western blot analysis with an anti-RhoA antibody. To verify equal loading, $15 \mu \mathrm{g}$ of cell lysates were run on separate gels and blots probed with an anti-RhoA antibody for total RhoA. ${ }^{*} P<0.05$ vs. control ( - TGF $\beta$ and - SU6656); ${ }^{*} P<0.05$ vs. TGF $\beta$-stimulated vehicle group. (C) RhoA knockdown reduces TGF $\beta$ activation of ATF2 but not Smad2. VSMCs were transfected with $20 \mathrm{nM}$ control siRNA or RhoA siRNA and then stimulated with or without TGF $\beta$ for $10 \mathrm{~min}$. Western blot analysis was performed to detect RhoA and phosphorylation of ATF2 and Smad2. ${ }^{\#} P<0.05$ vs. TGF $\beta$-stimulated siControl group. (D) RhoA knockdown reduces TGF $\beta$-induced CRP2 expression. VSMCs were transfected with $20 \mathrm{nM}$ control siRNA or RhoA siRNA and then stimulated with or without TGF $\beta$ for $24 \mathrm{~h}$. Western analysis was performed to detect RhoA and CRP2 protein levels. The membranes were subsequently probed with actin for loading control. ${ }^{\#} P<0.05$ vs. TGF $\beta$-stimulated siControl group. Representative blots of at least three independent experiments are shown.

Interestingly, SP600125 did not affect TGFß-induced Smad2 phosphorylation (Figure 6B). To determine whether JNK inhibition ultimately affected CRP2 induction by TGF $\beta$, we first pretreated VSMCs with vehicle or SP600125 for $30 \mathrm{~min}$, stimulated with or without TGF $\beta$ for $24 \mathrm{~h}$, then examined CRP2 expression levels. TGF $\beta$ induced CRP2 protein levels while SP600125 significantly reduced CRP2 levels (Figure 6C), suggesting JNK functions upstream of ATF2 to mediate CRP2 induction. Since unphosphorylated ATF2 is transcriptionally inactive, we overexpressed a constitutively active C2/ATF2 construct in VSMCs and examined CRP2 expression levels. Indeed, overexpression of C2/ATF2 increased CRP2 protein 1.5-fold (vs. vector control, $P<0.05$ ) (Figure 6D). Furthermore, C2/ATF2 rescued the TGF $\beta$ induction of CRP2 that was inhibited by JNK inhibitor SP600125 (Figure 6E), demonstrating the importance of JNK-ATF2 pathway in TGF $\beta$-mediated CRP2 induction. We next wanted to determine whether JNK functioned downstream of ROCK in the signaling pathway leading to ATF2 activation. Indeed, Y-27632 abrogated 


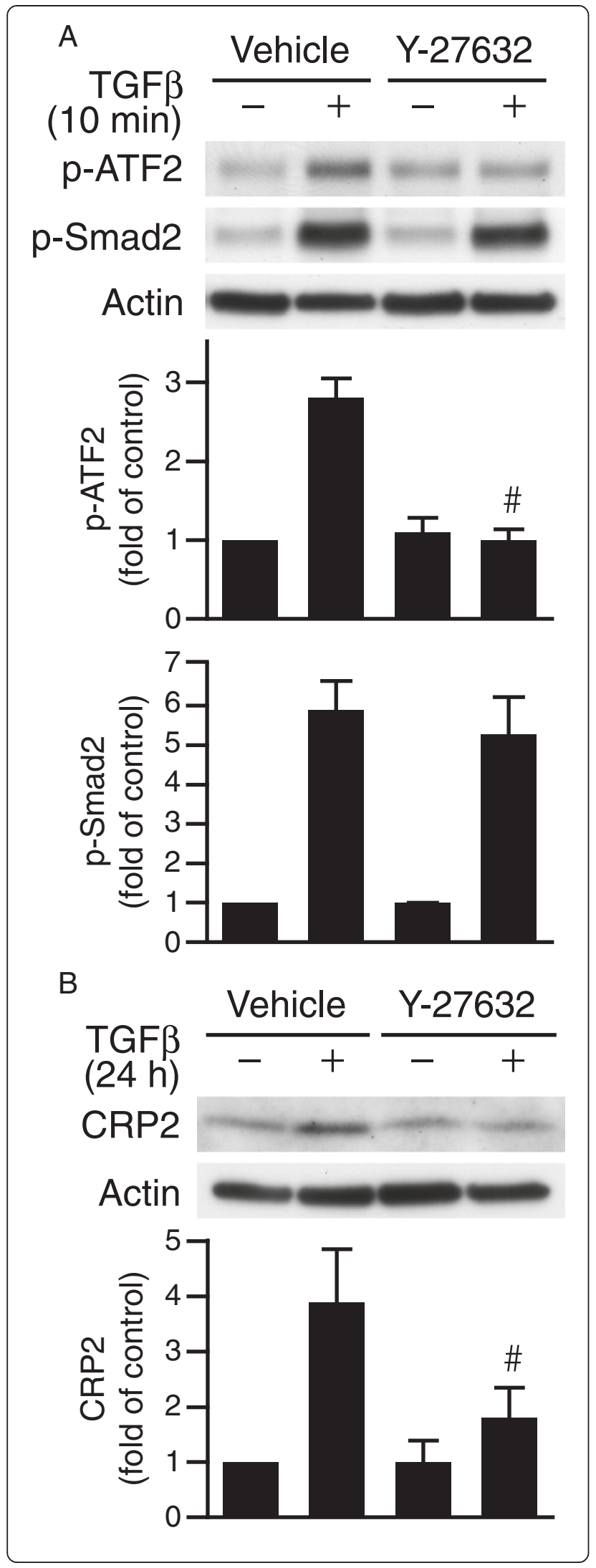

Figure 5 ROCK mediates Smad-independent ATF2 activation by TGF $\beta$. (A) VSMCs were pretreated with vehicle or ROCK inhibitor Y-27632 (10 $\mu \mathrm{M})$ for 30 min before stimulation with TGF $\beta$ for 10 min. Western blot analyses were then performed to examine phosphorylation of ATF2 and Smad2. ${ }^{\#} P<0.05$ vs. TGF $\beta$-stimulated vehicle group. (B) VSMCs were pretreated with vehicle or Y-27632 for 30 min before stimulation with or without TGF $\beta$ for $24 \mathrm{~h}$. CRP 2 expression was detected by Western blot analysis. ${ }^{\#} P<0.05$ vs. TGF $\beta$-stimulated vehicle group. Representative blots of at least three independent experiments are shown.

TGF $\beta$-induced JNK activation (Figure 6F), linking ROCKJNK-ATF2 signaling axis.

Both SBE and CRE sites are functionally important for basal and TGF $\beta$ induction of the Csrp2 promoter activity It is evident from our studies that Smad2/3 and ATF2 participate in the TGF $\beta$ induction of CRP2. As ATF2 activates Csrp2 transcription via CRE site [13], we set out to identify elements that are responsible for Smad2/3-mediated induction. Examination of the sequences within the mouse -795 bp Csrp 2 promoter (which is responsive to TGF $\beta$ ) revealed that in addition to the previously identified CRE site at bp -461 (Figure 7A, italic and underlined) there are two potential Smad binding elements (SBE), located at bp -681 and -445 (Figure 7A, bold and underlined), each with a base divergent from the consensus SBE (5'-GTCTAGAC-3'). To determine the potential function of these two putative SBE sites, we generated SBE mutant luciferase constructs, -795SBE681mut and -795SBE445mut, each with 3 bases mutated within the putative SBE sites (Figure 7B, left). We then transiently transfected VSMCs with parental wild-type luciferase plasmid -795Csrp2-luc and mutant constructs. Mutation of SBE681 did not affect either basal or TGF $\beta$ induction of Csrp2 promoter activity (Figure 7B). Similar to that of CRE mutation, SBE445 mutation not only decreased basal promoter activity but also reduced TGF $\beta$ responsiveness (Figure 7B). Double mutation of CRE and SBE445 further reduced promoter response (Figure 7B). These results indicate that both the SBE at bp -445 and CRE at -461 are functionally important in regulating Csrp2 transcription. Further supporting this notion, these two sites are completely conserved across species among human, mouse, and rat (Figure 7C).

To further demonstrate the critical roles of $\operatorname{Smad} 2 / 3$ and ATF2 in Csrp2 transcriptional regulation, we cotransfected luciferase plasmid -795Csrp2-luc with expression plasmids Smad2, C2/ATF2, or both in VSMCs and examined promoter activity. Smad2 slightly increased Csrp 2 promoter activity (1.5-fold, Figure 7D) although it did not reach a statistical significance, likely because Smad 2 might be inactive without TGF $\beta$ stimulation. Constitutively active C2/ ATF2 significantly increased Csrp2 promoter activity to 3.4-fold (Figure 7D). Interestingly, Smad2 and C2/ATF2 


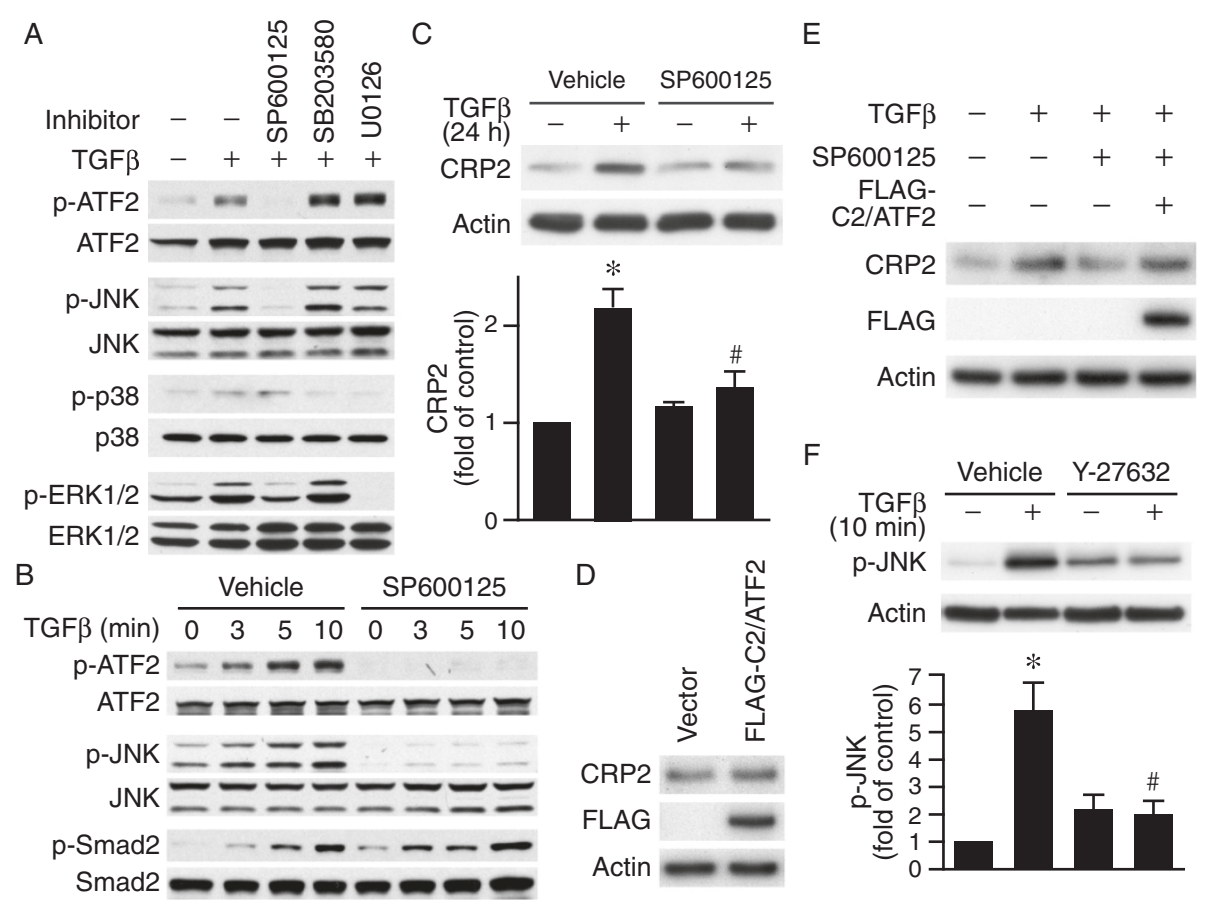

Figure 6 JNK activation is required for TGF $\beta$-induced ATF2 phosphorylation and CRP2 induction. (A) JNK activation is required for TGF $\beta$ induced phosphorylation of ATF2 but not Smad2/3. VSMCs were pretreated with vehicle, JNK inhibitor SP600125 (10 $\mu$ M), p38 inhibitor SB203580 $(10 \mu \mathrm{M})$, or ERK1/2 inhibitor U0126 $(10 \mu \mathrm{M})$ for $30 \mathrm{~min}$ before stimulation with TGF $\beta(10 \mathrm{ng} / \mathrm{ml})$. Phosphorylation of ATF2, JNK, p38, and ERK1/2 was determined $15 \mathrm{~min}$ after TGF $\beta$ stimulation. The membranes were subsequently probed with antibodies against total proteins for ATF2, JNK, p38, and ERK1/2 for loading control. (B) VSMCs were pretreated with vehicle or SP600125 for 30 min before stimulation with TGF $\beta$. Cell lysates were harvested at the indicated time points and the phosphorylation of ATF2, JNK, and Smad2 examined. The membranes were subsequently probed with antibodies against total proteins for ATF2, JNK, and Smad2 for loading control. (C) JNK activity contributes to CRP2 induction. VSMCS were pretreated with vehicle or SP600125 for 30 min before stimulation with TGF $\beta$ for $24 \mathrm{~h}$. Total proteins were then harvested for Western blot analysis to detect CRP2 expression. Values are mean \pm S.E. of at least three experiments. ${ }^{*} P<0.05$ vs. control $(-$ TGF $\beta) ;{ }^{\#} P<0.05$ vs. TGF $\beta$ stimulated vehicle group. (D) Constitutively active FLAG-C2/ATF2 increases CRP2 expression. VSMCs were electroporated with control vector or FLAG-C2/ATF2 and total proteins prepared $24 \mathrm{~h}$ later. Western blot analysis was performed to assess CRP2 levels. Overexpression of FLAG-C2/ ATF2 was evaluated by probing Western blots with FLAG antibody. (E) Overexpression of FLAG-C2/ATF2 rescues SP600125-inhibited TGF $\beta$ induction of CRP2. VSMCs were electroporated with control vector or FLAG-C2/ATF2, serum-starved, pretreated with vehicle or JNK inhibitor SP600125 for 30 min before stimulation with TGF $\beta$ for $24 \mathrm{~h}$. Western blot analysis was performed to assess CRP2 expression. FLAG-C2/ATF2 expression was evaluated with FLAG antibody. (F) VSMCs were pretreated with vehicle or ROCK inhibitor Y-27632 (10 $\mu \mathrm{M})$ for 30 min before stimulation with or without TGF $\beta$ for $10 \mathrm{~min}$. Phospho-JNK expression was detected by Western blot analysis. The membranes were subsequently probed with actin for loading control. ${ }^{*} P<0.05$ vs. control $(-$ TGF $\beta) ;{ }^{~} P<0.05$ vs. TGF $\beta$-stimulated vehicle group. Representative blots of at least three independent experiments are shown.

together enhanced Csrp2 promoter activity to 19-fold (Figure 7D), indicating a synergistic effect of these two factors. Next, we performed real-time PCR to examine the effects of Smad2 and C2/ATF2 on CRP2 mRNA levels. Similar to promoter activity, Smad2 slightly increased while C2/ATF2 increased CRP2 mRNA levels to 2-fold (Figure 7E). In addition, Smad2 and C2/ATF2 synergistically induced CRP2 mRNA levels (Figure 7E).

\section{Discussion}

CRP2 plays a critical role in attenuating the development of arteriosclerosis [3,4]. Upregulating CRP2 in the injured artery may protect against neointima formation. The goal of this study was to identify mechanisms and signaling pathways that sustain or upregulate CRP2 expression to decrease vascular disease. We show that activation of both Smad2/3 and ATF2 are essential for enhancing CRP2 expression. Unlike the TRRI-dependent Smad pathway, Src family kinase-RhoA-ROCK-JNK signaling axis mediates T $\beta R I-i n d e p e n d e n t ~ A T F 2$ activation. The TGF $\beta$ induction of CRP2 is mediated through the CRE and SBE promoter elements. Our results demonstrate that two signaling axes downstream of TGF $\beta$ converge on Csrp2 promoter to cooperatively control CRP2 induction in VSMCs.

Smad proteins function as intracellular TGF $\beta$ signaling effectors. Following activation and translocation into the nucleus, the heterotrimeric Smad complex recognizes and binds to SBE site to activate target gene expression [26]. Consistent with this canonical signaling pathway, we found in VSMCs that TGF $\beta$ activated Smad2/3 to 


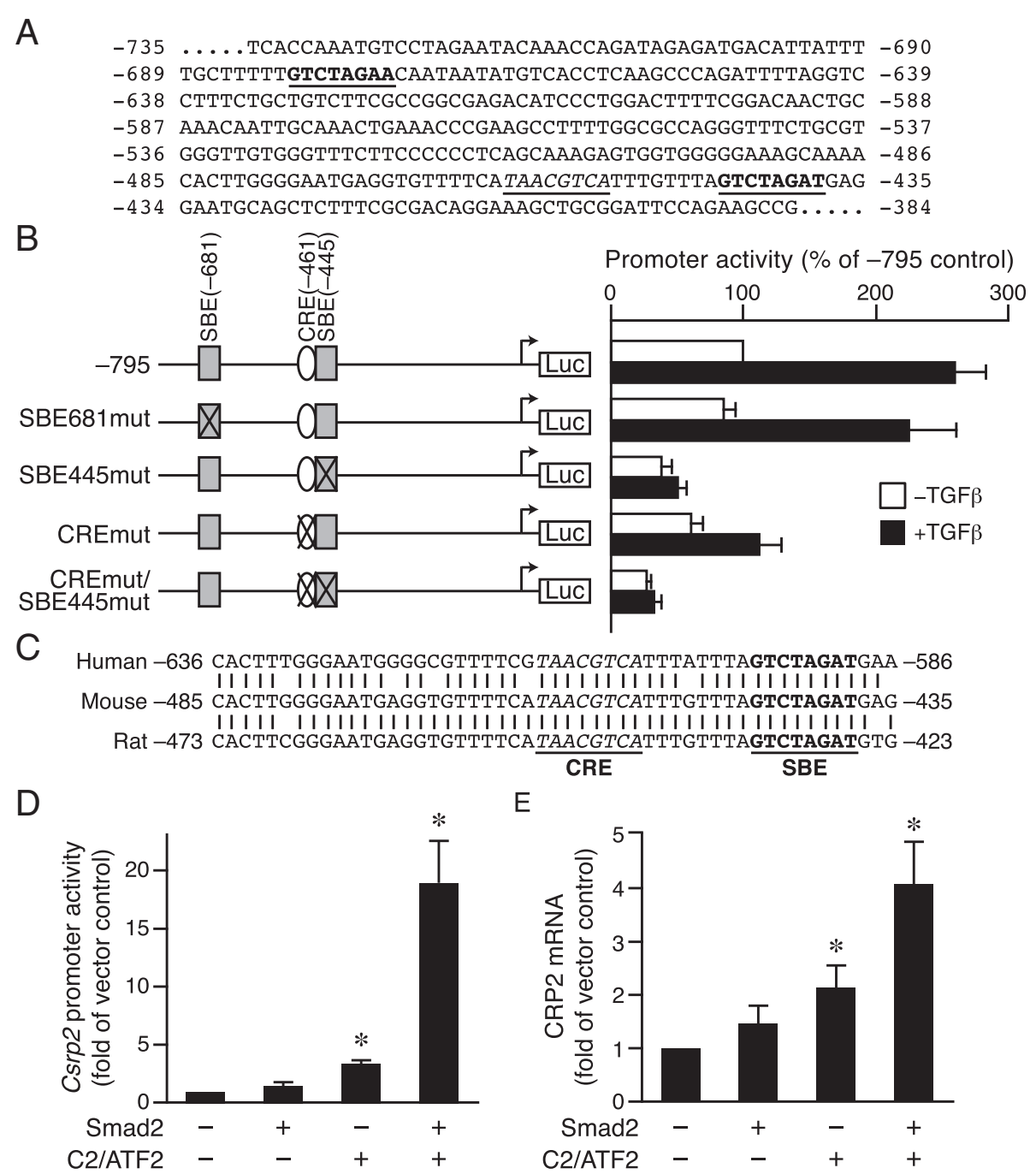

Figure 7 SBE445 and CRE461 are functionally important for basal and TGF $\beta$-induced Csrp2 promoter activity. (A) Two putative SBE sites at bp -681 and -445 of the mouse Csrp2 promoter (bold and underlined). The CRE site at -461 is also indicated (italic and underlined). (B) The putative SBE site at -445 and CRE at -461 are important for Csrp2 promoter activity. The -795 Csrp2 wild type and SBE and CRE mutant promoter constructs are schematically depicted in the left panel. VSMCs were transiently transfected with Csrp2 luciferase reporter constructs containing -795, SBE681mut, SBE445mut, CREmut, or CREmut/SBE445mut in triplicate using FuGENE 6 transfection reagent. Two hours after transfection, cells were treated with or without TGF $\beta(10 \mathrm{ng} / \mathrm{ml})$ for $24 \mathrm{~h}$. Cells were then harvested for luciferase activity and protein assays. Luciferase activity is expressed relative to -795 without TGF $\beta$ treatment. Values are mean \pm S.E. of at least three experiments. (C) Conservation of the CRE and SBE sites among species. Sequence alignment of the corresponding regions of human and rat promoter sequences to the mouse promoter. The CRE site is in italic and SBE site in bold type. (D) VSMCs were transiently cotransfected with -795Csrp2-luc reporter with empty vector or expression plasmids Smad2, C2/ATF2, or both. Cells were then harvested $24 \mathrm{~h}$ later for luciferase activity and protein assays. Luciferase activity is expressed relative to -795 with empty expression vector. Values are mean \pm S.E. of at least three experiments. ${ }^{*} P<0.05$ vs. empty expression vector. (E) VSMCS were electroporated with control vector or expression plasmids Smad2, C2/ATF2, or both. Total RNA was prepared $12 \mathrm{~h}$ later for real-time PCR analysis to assess CRP2 mRNA expression and $\beta$-actin was used as an internal control for normalization. Quantification was performed by the comparative $C_{T}$ method. CRP2 mRNA is expressed relative to empty expression vector. Values are mean \pm S.E. of at least three experiments. ${ }^{*} P<0.05$ vs. empty expression vector.

induce CRP2 expression via a SBE site at bp -445 of the Csrp2 promoter (Figures 1 and 7). This Smad2/3 activation is dependent on T $\beta R I$ and its kinase activity, as siTßRI or SB431542 inhibited TGF $\beta$-induced Smad2/3 phosphorylation (Figures 1 and 3). TGF $\beta$ also activated ATF2 to induce CRP2 expression ([13] and Figure 1).
The fact that ATF2 phosphorylation was not affected either by inhibiting T $\beta R I$ kinase activity or knocking down T $\beta R I$ expression (Figures $1 \mathrm{~B}$ and $3 \mathrm{~A}$ ) indicated that T $\beta R I$ was dispensable for ATF2 activation. By contrast, T $\beta$ RII was required for both Smad2 and ATF2 activation (Figure $3 \mathrm{C}$ ). Intriguingly, although it was expected 
that overexpression of DN-TBRII inhibited Smad2 phosphorylation (because it lacks cytoplasmic C-terminal kinase domain and is unable to activate T $\beta R I$ ) DN-T $\beta$ RII failed to inhibit ATF2 phosphorylation (Figure 3D). Taken together, these results suggest that in VSMCs T $\beta$ RII alone is able to mediate TGF $\beta$ signaling to ATF2 and the cytoplasmic do-

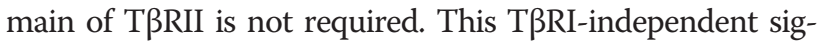
naling to ATF2 is similar to the findings in dermal cells that T $\beta R$ II directly activates ERK $1 / 2$ without the participation of T $\beta R I$ [27] and supports the notion that TGF $\beta$ receptors can activate non-Smad proteins and allow Smadindependent TGF $\beta$ responses [28].

We found JNK functioned upstream of ATF2 in the TGF $\beta$ induction of CRP2 (Figure 6); however, JNK inhibition did not affect Smad2/3 activation (Figure 6B). These results are in contrast to the findings in Mv1Lu epithelial cells and T98G glioblastoma cells $[29,30]$. In epithelial cells, while TGF $\beta$ activates both Smad3 and JNK there is an interdependent Smad and JNK signaling because activated JNK in turn phosphorylates Smad3 [29]. In glioblastoma cells [30], TGF $\beta$ activates p38 MAPK and ATF2 but does not induce JNK phosphorylation; furthermore, inhibition of p38 MAPK decreases TGF $\beta$-induced phosphorylation of ATF2 and Smad2. Those findings indicate an interaction between Smad and p38 MAPK pathways downstream of TGF $\beta$ [30] that are in contrast to our results that p38 MAPK and ERK1/2 are not involved in ATF2 activation (Figure 6A). Our current findings and these previous reports suggest that TGF $\beta$ signaling pathways are likely to be cell type specific.

We demonstrated that both CRE and SBE sites contribute to CRP2 upregulation by TGF $\beta$ (Figure 7). Importantly, these two sites are completely conserved across species among human, mouse, and rat (Figure 7C), suggesting the critical importance of the CRE and SBE in the regulation of Csrp2 transcription. The importance of CRE in mediating TGF $\beta$ target gene induction was shown in a rat intestinal epithelial cell line 4-1 that transcription factors CREB-1, ATF2, c-Jun, and Smad3 all bind to the CRE site to activate transcription [31]. Interestingly, ATF2, via its basic leucine zipper region, was shown to bind to the MH1 domain of the Smad proteins [32]. TGF $\beta$ stimulation further enhances the association of ATF2 and Smad3/4 and increases the CRE-containing reporter activity in HepG2 cells [32]. Since blocking either the ATF2-CRE or TRRISmad2/3 axis significantly reduced CRP2 expression (Figures 1 and 7) and given the proximity of CRE and SBE sites (8 bp apart), it is possible that Smad heterotrimer and ATF2 might form a higher order complex to cooperatively, rather than independently, regulate CRP2 expression. This regulation via two cis elements is similar to that of several SMC marker genes [33]. For example, the TGF $\beta$ induction of SM $\alpha$ - actin and SM22 $\alpha$ expression is coordinately regulated by a TGF $\beta$ control element (TCE) and nearby CArG $\left(\mathrm{CC}(\mathrm{A} / \mathrm{T})_{6} \mathrm{GG}\right)$ elements in the $5^{\prime}$ promoter $[33,34]$. However, the regulatory mechanism of CRP2 expression by TGF $\beta$ differ from these SMC marker genes in that CRP2 induction is mediated through the CRE and SBE elements whereas TCE and CArG elements mediate the TGF $\beta$ induction of SM $\alpha$-actin and SM $22 \alpha$ expression.

\section{Conclusion}

Based on our findings, we propose that two signaling pathways downstream of TGF $\beta$ converge on Csrp 2 promoter to cooperatively induce Csrp 2 gene transcription and protein expression (Figures 1, 7, and 8). In the canonical pathway, upon TGF $\beta$ binding, T $\beta$ RII trans-phosphorylates T $\beta R I$ to activate its kinase function, leading to $\operatorname{Smad} 2 / 3$ phosphorylation. Activated Smad2/3 then cooperate with Smad4 to form a complex, translocates into the nucleus and bind to SBE of the Csrp 2 promoter. In the noncanonical signaling pathway that does not require T $\beta R I$, TGF $\beta$ binds to T $\beta R I I$ and activates Src family kinase and RhoA signaling. Activated ROCK in turn phosphorylates JNK, resulting in ATF2 activation. Activated ATF2 dimer then binds to the CRE site 8 bp upstream of SBE on the Csrp 2 promoter. The ATF2 on the CRE site and Smad proteins on the SBE site might associate to form a higher order complex to cooperatively enhance CRP2 expression (Figure 8) in VSMCs, which represents a previously unrecognized mechanism of VSMC gene induction by TGF $\beta$.

\section{Methods}

\section{Luciferase reporter and expression constructs}

The -795Csrp2-luc luciferase reporter plasmid was described previously [35] and used as a template to generate mutant constructs. Site-directed mutagenesis was performed using Pfu polymerase (Stratagene) to mutate the putative SBE sites at -681 from GTCTAGAA to CTATCGAA and at -445 from GTCTAGAT to CTATCGAT (mutated bases are italicized) to generate SBE681mut and SBE445mut constructs, respectively. The CREmut/SBE445mut construct with double mutations at -461CRE and 445SBE was generated using -795CREmutCsrp2-luc [13] as a template to mutate putative $-445 \mathrm{SBE}$ site as above. All constructs were confirmed by DNA sequencing. Dominant-negative mutant of type II TGF $\beta$ receptor pCMV5 HA-T $\beta$ RII $(\Delta C y t)$ that lacks C-terminal kinase domain and is unable to activate T $\beta R I$ [20] was obtained from Addgene (plasmid 14051). The expression plasmid pCMV5-Smad2 has previously been described [36]. The constitutively active mutant construct FLAG-C2/ ATF2 [37] that contains a FLAG tag at the N-terminus, followed by the constitutively active activation domain 


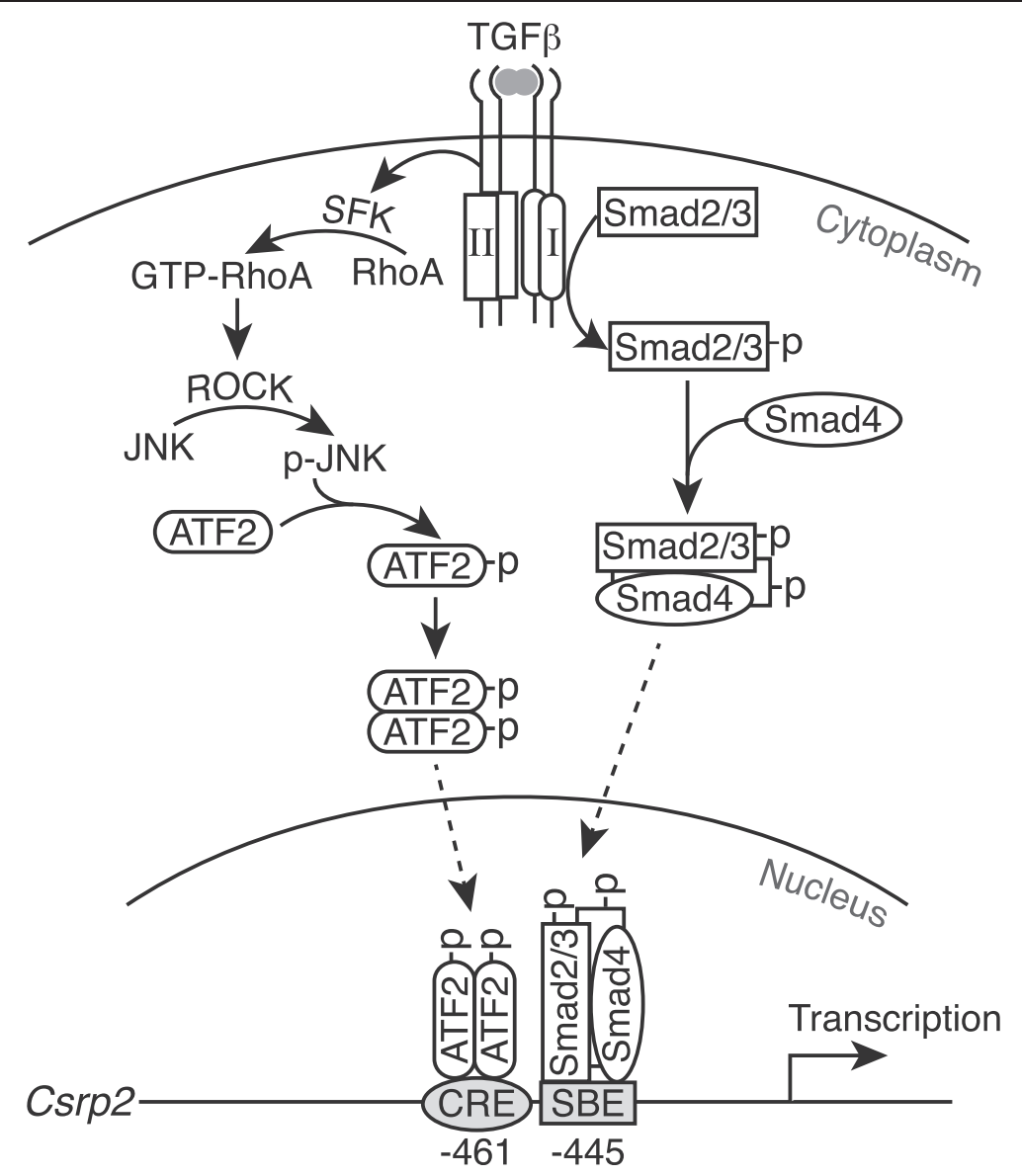

Figure 8 Schematic model of TGF $\beta$ signaling pathways for CRP2 induction in VSMCs. Upon TGF $\beta$ stimulation, two signaling axes are activated: the canonical TRRI-dependent Smad2/3 pathway and the non-canonical ATF2 pathway. In the canonical pathway, activated Smad2/3 form a complex with Smad4, translocates into the nucleus, and binds to SBE site at -445 of the Csrp2 promoter. In the non-canonical pathway, following TBRII binding of TGF $\beta$, T $\beta R I I$ (without the requirement of TBRII's cytoplasmic kinase domain) activates Src family kinase (SFK), which in turn activates RhoA. Enhanced RhoA activation leads to ROCK activation and increased JNK phosphorylation, resulting in enhanced ATF2 phosphorylation. Activated ATF2 dimer binds to CRE site at -461. The two signaling pathways (ATF2 and Smad) converge on the CRE and SBE sites of the Csrp2 promoter to cooperatively control CRP2 induction in VSMCs, which represents a previously unrecognized mechanism of VSMC gene induction by TGF $\beta$.

of CREB2 and the DNA binding and dimerization domains of ATF2 was generously provided by G. Thiel (University of the Saarland Medical Center, Homburg, Germany).

\section{VSMC primary culture and transient transfection assays}

Primary VSMCs were isolated from mouse aortas and cultured in Dulbecco's modified Eagle's medium (DMEM) as described [38]. Cells of passages 5-8 were used for experiments. The day before transfection, approximately 160,000 VSMCs were plated onto each well of 6-well plates. Cells were then transfected with various luciferase reporter constructs $(1 \mu \mathrm{g} /$ well $)$ in triplicates by using FuGENE 6 or XtremeGENE 9 according to the manufacturer's instructions (Roche). Two hours following transfection, cells were treated with or without TGF $\beta$ (PeproTech, $10 \mathrm{ng} / \mathrm{ml}$ ). Luciferase activities were measured $24 \mathrm{~h}$ later using Luciferase Assay System (Promega) and normalized to total protein content. To evaluate the effect of Smad2 and
ATF2 on promoter activity, cells were cotransfected with -795Csrp2-luc $(0.33 \mu \mathrm{g} /$ well $)$ and $0.67 \mu \mathrm{g} /$ well of expression plasmid (empty vector, CMV5-Smad2, FLAG-C2/ ATF2, or Smad2 + C2/ATF2) and luciferase activity measured $24 \mathrm{~h}$ later.

For overexpression experiments, VSMCs were electroporated with vector control or expression plasmid Smad2, C2/ATF2, or Smad2 + C2/ATF2 (8 $\mu \mathrm{g}$ DNA $/ 1 \times 10^{6}$ cells $)$ with Gene Pulser Xcell ${ }^{\text {Tu }}$ Electroporation System (Bio-Rad) using $400 \mathrm{~V}, 10 \mathrm{~ms}$, square wave parameters. Following recovery, cells were serum starved (0.5\% FBS in DMEM) and total RNA or protein isolated at indicated time points for real time-PCR or Western blot analysis. For dominantnegative TRRII experiments, VSMCs were electroporated with pCMV5 vector or pCMV5 HA-T $\beta$ RII $(\Delta C y t)$, serum starved, treated with or without TGF $\beta$, and then total proteins isolated for Western blot analysis at different time points. 


\section{Western blot analysis}

To evaluate the effects of TGF $\beta$ on protein expressions and downstream signaling, VSMCs were plated and incubated overnight. Following serum-starvation $(0.5 \%$ FBS in DMEM) for $24 \mathrm{~h}$, cells were stimulated with or without TGF $\beta$. Total proteins were prepared at the indicated time points using extraction buffer containing protease inhibitor Complete ${ }^{\mathrm{TM}}$ (Roche) and Halt ${ }^{\mathrm{TM}}$ Phosphatase Inhibitor Cocktail (Thermo Scientific) for Western blot analysis as described [13]. To inhibit various kinase activities, VSMCs were treated with inhibitors $30 \mathrm{~min}$ prior to stimulation with or without TGF $\beta$. SB431542 (Calbiochem) was used for inhibiting T $\beta R I$ kinase activity, Wortmannin and LY294002 (Calbiochem) for PI3K, SP600125 (Calbiochem) for JNK, SB203580 (Calbiochem) for p38, U0126 (Calbiochem) for ERK1/2, Y-27632 (Calbiochem) for ROCK, and SU6656 (Sigma-Aldrich) for inhibiting Src family kinase activity.

To assess phosphorylated and total protein of signaling molecules, membranes were incubated with antibodies against respective phospho- or total protein. The following antibodies were purchased from Cell Signaling Technology: phospho-ATF2 (Thr ${ }^{71}$, \#9221), phospho-Smad2 ( $\mathrm{Ser}^{465 / 467}$, \#3108), phospho-Smad3 (Ser ${ }^{423 / 425}$, \#9520), Smad2/3 (\#3102), phospho-JNK Thr ${ }^{183} / \mathrm{Tyr}^{185}$ (\#9251), JNK (\#9252), phospho-p38 Thr $^{180} / \mathrm{Tyr}^{182}$ (\#9211), p38 (\#9212), phosphoERK1/2 $\mathrm{Thr}^{202} / \mathrm{Tyr}^{204}$ (\#9101), ERK1/2 (\#9102), and TßRIII (\#2519). ATF2(C19) antibody (Santa Cruz Biotechnology) was used to detect total ATF2. CRP2-(91-98) antiserum [13] was used for CRP2 protein detection. TAK1 and TRAF6 antibodies (Santa Cruz Biotechnology) were used to detect TAK1 and TRAF6 expression. To detect dominant-negative T $\beta$ RII (HA-T $\beta$ RII $(\Delta$ Cyt)) expression, an anti-HA tag antibody (114-2C-7) (Millipore, \#05-902R) was used. Antibodies TßRI (V-22) (Santa Cruz Biotechnology), T $\beta$ RII (L-21) (Santa Cruz Biotechnology), and TßRIII (Cell Signaling Technology, \#2519) were used to detect endogenous T $\beta R I, T \beta R I I$, and T $\beta$ RIII expression, respectively. A mouse monoclonal anti-FLAG antibody (Sigma, \#F9291) was used to detect FLAG-C2/ATF2 expression. To verify equivalent loading, membranes were subsequently incubated with an actin antibody (Millipore, MAB1501).

\section{siRNA knockdown}

To suppress mRNA levels of Smad2/3, ATF2, TAK1,

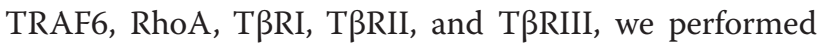
knockdown experiments with small interfering RNA (siRNA). The ON-TARGET plus SMART pool siRNAs and negative control siRNA were obtained from Dharmacon. VSMCs $\left(2.8 \times 10^{5}\right.$ cells $)$ were plated on $60-\mathrm{mm}$ dish and after overnight incubation, cells were transfected with $20 \mathrm{nM}$ of negative control or target siRNA in Opti-MEM $^{\ominus}$ I Reduced Serum Medium using
Lipofectamine RNAiMAX as described by the manufacturer's protocol (Life Technologies).

\section{Assessment of RhoA activation}

RhoA activation was assessed using an Active Rho Pull-Down and Detection Kit (Thermo Scientific) by immunoprecipitating GTP-bound RhoA with GST fusion protein of Rhotekin RhoA binding domain (GSTRhotekin-RBD). Briefly, VSMCs plated in 150-mm dish were washed with ice-cold PBS and lysed in buffer containing $25 \mathrm{mM}$ Tris pH 7.2, $150 \mathrm{mM} \mathrm{NaCl}, 5 \mathrm{mM} \mathrm{MgCl}_{2}, 1 \%$ NP-40, and 5\% glycerol. Cell lysates $(500 \mu \mathrm{g})$ were incubated with $400 \mu \mathrm{g}$ of GST-Rhotekin-RBD and glutathione resin at $4{ }^{\circ} \mathrm{C}$ for $1 \mathrm{~h}$. Following washing, bound Rho was eluted by SDS sample buffer. The eluted samples and the total cell lysates were then subjected to Western blot analysis with RhoA antibody (26C4) (SantaCruz Biotechnology, sc-418) to detect active and total RhoA, respectively.

\section{Quantitative real time-PCR}

Total RNA was isolated using an RNeasy Mini kit (QIAGEN) according to the manufacturer's instructions. One $\mu \mathrm{g}$ RNA was first reverse transcribed to cDNA with random primers using SuperScript III reverse transcriptase (Invitrogen). Quantitative real time-PCR was performed with the transcribed cDNA and $\mathrm{SYBR}^{\bullet}$ FAST Universal $2 \mathrm{X}$ qPCR Master Mix (KAPA) in triplicates using the 7500 real time PCR system (Applied Biosystems) to detect CRP2 mRNA expression. The primers used for CRP2 are: forward, 5' -CTGACTGAGAAAGAAGGCGAAATC-3' and reverse, 5' -TGCTGGCTGTTTCACAGTAGTGA-3'. $\beta$ actin was used as an internal control for normalization with the following primers: forward, 5'-GAGAGGTATCCTGACCCTGAAG-3'; reverse, 5' -TGATCTGGGTCATCTT TTCACGG-3'. Quantification was performed by the comparative $\mathrm{C}_{\mathrm{T}}$ method.

\section{Statistical analysis}

Data are presented as mean \pm S.E. of at least three independent experiments. All results were analyzed statistically by Student's $t$-test. $P$ values $<0.05$ are considered statistically significant.

\footnotetext{
Abbreviations

CArG element: CC(A/T) ${ }_{6} \mathrm{GG}$; CRE: Cyclic AMP response element; CRP2: Cysteine-rich protein 2; Csrp2: Mouse CRP2 gene symbol; ROCK: RhoA kinase; SBE: Smad binding element; siRNA: Small interfering RNA; SM: Smooth muscle; T $\beta R$ : TGF $\beta$ receptor; TCE: TGF $\beta$ control element; VSMCs: Vascular smooth muscle cells.

Competing interests

The authors declare no competing interests.

Authors' contributions

MLW, CHC, YTL, YJJ, and YCH performed experiments, MLW, LTY, LC, MDL, and SFY analyzed and interpreted the data, MLW, MDL, and SFY prepared the figures. MLW, MDL, and SFY designed the research and wrote the manuscript. All authors had a final approval of the manuscript.
} 


\section{Acknowledgements}

This research was conducted under the Graduate Program of Biotechnology in Medicine sponsored by the National Tsing Hua University and the National Health Research Institutes. This work was supported by the National Science Council (Taiwan) (101-2320-B-400-002-MY3 and 102-2321-B-400-020 to S.F.Y.); National Health Research Institutes (CS-103-PP-05 to S.F.Y.); and the National Institutes of Health (HL-078869 to M.D.L.).

\section{Author details}

'Institute of Cellular and System Medicine, National Health Research Institutes, Zhunan, Taiwan. ${ }^{2}$ Institute of Molecular Medicine, National Tsing Hua University, Hsinchu, Taiwan. ${ }^{3}$ Department of Medical Science and Institute of Bioinformatics and Structural Biology, National Tsing Hua University, Hsinchu, Taiwan. ${ }^{4}$ Graduate Institute of Life Sciences, National Defense Medical Center, Taipei, Taiwan. ${ }^{5}$ Department of Biochemistry, Boston University School of Medicine, Boston, Massachusetts, USA. 'Metabolomic Research Center, China Medical University Hospital, Taichung, Taiwan. ${ }^{7}$ Graduate Institute of Basic Medical Science, China Medical University, Taichung, Taiwan.

\section{Received: 15 November 2013 Accepted: 23 March 2014}

Published: 28 March 2014

\section{References}

1. Owens GK, Kumar MS, Wamhoff BR: Molecular regulation of vascular smooth muscle cell differentiation in development and disease. Physiol Rev 2004, 84:767-801.

2. Louis HA, Pino JD, Schmeichel KL, Pomies P, Beckerle MC: Comparison of three members of the cysteine-rich protein family reveals functional conservation and divergent patterns of gene expression. J Biol Chem 1997, 272:27484-27491.

3. Jain MK, Fujita KP, Hsieh CM, Endege WO, Sibinga NE, Yet SF, Kashiki S, Lee WS, Perrella MA, Haber E, Lee ME: Molecular cloning and characterization of SmLIM, a developmentally regulated LIM protein preferentially expressed in aortic smooth muscle cells. J Biol Chem 1996, 271:10194-10199.

4. Wei J, Gorman TE, Liu X, Ith B, Tseng A, Chen Z, Simon DI, Layne MD, Yet SF: Increased neointima formation in cysteine-rich protein 2-deficient mice in response to vascular injury. Circ Res 2005, 97:1323-1331.

5. Chen $\mathrm{CH}$, Ho YC, Ho HH, Chang IC, Kirsch KH, Chuang YJ, Layne MD, Yet SF: Cysteine-rich protein 2 alters 130 Cas localization and inhibits vascular smooth muscle cell migration. Cardiovasc Res 2013, 100:461-471.

6. Majesky MW, Lindner V, Twardzik DR, Schwartz SM, Reidy MA: Production of transforming growth factor $\beta_{1}$ during repair of arterial injury. J Clin Invest 1991, 88:904-910.

7. Yamamoto K, Morishita R, Tomita N, Shimozato T, Nakagami H, Kikuchi A, Aoki M, Higaki J, Kaneda Y, Ogihara T: Ribozyme oligonucleotides against transforming growth factor- $\beta$ inhibited neointimal formation after vascular injury in rat model: potential application of ribozyme strategy to treat cardiovascular disease. Circulation 2000, 102:1308-1314.

8. Grainger DJ, Kemp PR, Metcalfe JC, Liu AC, Lawn RM, Williams NR, Grace AA, Schofield PM, Chauhan A: The serum concentration of active transforming growth factor- $\beta$ is severely depressed in advanced atherosclerosis. Nat Med 1995, 1:74-79.

9. Mack CP: Signaling mechanisms that regulate smooth muscle cell differentiation. Arterioscler Thromb Vasc Biol 2011, 31:1495-1505.

10. Guo $X$, Chen SY: Transforming growth factor- $\beta$ and smooth muscle differentiation. World J Biol Chem 2012, 3:41-52.

11. Mallat Z, Gojova A, Marchiol-Fournigault C, Esposito B, Kamate C, Merval R, Fradelizi $D$, Tedgui A: Inhibition of transforming growth factor- $\beta$ signaling accelerates atherosclerosis and induces an unstable plaque phenotype in mice. Circ Res 2001, 89:930-934.

12. Kobayashi K, Yokote K, Fujimoto M, Yamashita K, Sakamoto A, Kitahara M, Kawamura H, Maezawa Y, Asaumi S, Tokuhisa T, Mori S, Sato Y: Targeted disruption of TGF- $\beta$-Smad3 signaling leads to enhanced neointimal hyperplasia with diminished matrix deposition in response to vascular injury. Circ Res 2005, 96:904-912.

13. Lin DW, Chang IC, Tseng A, Wu ML, Chen CH, Patenaude CA, Layne MD, Yet SF: Transforming growth factor $\beta$ up-regulates cysteine-rich protein 2 in vascular smooth muscle cells via activating transcription factor 2 . J Biol Chem 2008, 283:15003-15014.

14. Derynck R, Feng XH: TGF- $\beta$ receptor signaling. Biochim Biophys Acta 1997, 1333:F105-150.
15. Wygrecka M, Zakrzewicz D, Taborski B, Didiasova M, Kwapiszewska G, Preissner $K T$, Markart P: TGF- $\beta 1$ induces tissue factor expression in human lung fibroblasts in a PI3K/JNK/Akt-dependent and AP-1-dependent manner. Am J Respir Cell Mol Biol 2012, 47:614-627.

16. Sorrentino A, Thakur N, Grimsby S, Marcusson A, von Bulow V, Schuster N, Zhang $\mathrm{S}$, Heldin $\mathrm{CH}$, Landstrom M: The type I TGF- $\beta$ receptor engages TRAF6 to activate TAK1 in a receptor kinase-independent manner. Nat Cell Biol 2008, 10:1199-1207.

17. Yamashita M, Fatyol $K$, Jin C, Wang X, Liu Z, Zhang YE: TRAF6 mediates Smad-independent activation of JNK and p38 by TGF- $\beta$. Mol Cell 2008, 31:918-924

18. Siegel PM, Massague J: Cytostatic and apoptotic actions of TGF- $\beta$ in homeostasis and cancer. Nat Rev Cancer 2003, 3:807-821.

19. Lopez-Casillas F, Wrana JL, Massague J: Betaglycan presents ligand to the TGF $\beta$ signaling receptor. Cell 1993, 73:1435-1444.

20. Siegel PM, Shu W, Cardiff RD, Muller WJ, Massague J: Transforming growth factor $\beta$ signaling impairs Neu-induced mammary tumorigenesis while promoting pulmonary metastasis. Proc Natl Acad Sci U S A 2003, 100:8430-8435.

21. Papadimitriou E, Kardassis D, Moustakas A, Stournaras C: TGF $\beta$-induced early activation of the small GTPase RhoA is Smad2/3-independent and involves Src and the guanine nucleotide exchange factor Vav2. Cell Physiol Biochem 2011, 28:229-238.

22. Sato M, Kawai-Kowase K, Sato H, Oyama Y, Kanai H, Ohyama Y, Suga T, Maeno T, Aoki Y, Tamura J, Sakamoto H, Nagai R, Kurabayashi M: c-Src and hydrogen peroxide mediate transforming growth factor- $\beta 1$-induced smooth muscle cell-gene expression in $10 \mathrm{~T} 1 / 2$ cells. Arterioscler Thromb Vasc Biol 2005, 25:341-347.

23. Chen S, Crawford M, Day RM, Briones VR, Leader JE, Jose PA, Lechleider RJ: RhoA modulates Smad signaling during transforming growth factor- $\beta$ induced smooth muscle differentiation. J Biol Chem 2006, 281:1765-1770.

24. Deaton RA, Su C, Valencia TG, Grant SR: Transforming growth factor- $\beta 1$-induced expression of smooth muscle marker genes involves activation of PKN and p38 MAPK. J Biol Chem 2005, 280:31172-31181.

25. Zhang YE: Non-Smad pathways in TGF- $\beta$ signaling. Cell Res 2009, 19:128-139.

26. Zawel L, Dai JL, Buckhaults P, Zhou S, Kinzler KW, Vogelstein B, Kern SE: Human Smad3 and Smad4 are sequence-specific transcription activators. Mol Cell 1998, 1:611-617.

27. Bandyopadhyay B, Han A, Dai J, Fan J, Li Y, Chen M, Woodley DT, Li W: TRRI/Alk5-independent T $\beta R$ II signaling to ERK1/2 in human skin cells according to distinct levels of TRRII expression. J Cell Sci 2011, 124:19-24.

28. Moustakas A, Heldin CH: Non-Smad TGF- $\beta$ signals. J Cell Sci 2005, 118:3573-3584.

29. Engel ME, MCDonnell MA, Law BK, Moses HL: Interdependent SMAD and JNK signaling in transforming growth factor- $\beta$-mediated transcription. J Biol Chem 1999, 274:37413-37420.

30. Dziembowska M, Danilkiewicz M, Wesolowska A, Zupanska A, Chouaib S, Kaminska B: Cross-talk between Smad and p38 MAPK signalling in transforming growth factor $\beta$ signal transduction in human glioblastoma cells. Biochem Biophys Res Commun 2007, 354:1101-1106.

31. Liu G, Ding W, Neiman J, Mulder KM: Requirement of Smad3 and CREB-1 in mediating transforming growth factor- $\beta$ (TGF $\beta$ ) induction of TGF $\beta 3$ secretion. J Biol Chem 2006, 281:29479-29490.

32. Sano Y, Harada J, Tashiro S, Gotoh-Mandeville R, Maekawa T, Ishii S: ATF-2 is a common nuclear target of Smad and TAK1 pathways in transforming growth factor- $\beta$ signaling. J Biol Chem 1999, 274:8949-8957.

33. Hautmann MB, Madsen CS, Owens GK: A transforming growth factor $\beta$ (TGF $\beta$ ) control element drives TGF $\beta$-induced stimulation of smooth muscle $a$-actin gene expression in concert with two CArG elements. J Biol Chem 1997, 272:10948-10956.

34. Adam PJ, Regan CP, Hautmann MB, Owens GK: Positive- and negativeacting Krüppel-like transcription factors bind a transforming growth factor $\beta$ control element required for expression of the smooth muscle cell differentiation marker SM22a in vivo. J Biol Chem 2000, 275:37798-37806.

35. Chang YF, Wei J, Liu X, Chen YH, Layne MD, Yet SF: Identification of a CArG-independent region of the cysteine-rich protein 2 promoter that directs expression in the developing vasculature. Am J Physiol Heart Circ Physiol 2003, 285:H1675-1683.

36. Hayashi H, Abdollah S, Qiu Y, Cai J, Xu YY, Grinnell BW, Richardson MA, Topper JN, Gimbrone MA Jr, Wrana JL, Falb D: The MAD-related protein 
Smad7 associates with the TGF $\beta$ receptor and functions as an antagonist of TGF $\beta$ signaling. Cell 1997, 89:1165-1173.

37. Steinmuller $L$, Thiel $G$ : Regulation of gene transcription by a constitutively active mutant of activating transcription factor 2 (ATF2). Biol Chem 2003, 384:667-672.

38. Gunther S, Alexander RW, Atkinson WJ, Gimbrone MA Jr: Functional angiotensin II receptors in cultured vascular smooth muscle cells. J Cell Biol 1982, 92:289-298.

doi:10.1186/1478-811X-12-22

Cite this article as: Wu et al.: Divergent signaling pathways

cooperatively regulate TGF $\beta$ induction of cysteine-rich protein 2 in

vascular smooth muscle cells. Cell Communication and Signaling

2014 12:22.

\section{Submit your next manuscript to BioMed Central and take full advantage of:}

- Convenient online submission

- Thorough peer review

- No space constraints or color figure charges

- Immediate publication on acceptance

- Inclusion in PubMed, CAS, Scopus and Google Scholar

- Research which is freely available for redistribution 